\title{
Promoting Healthy Decision-Making via Natural Environment Exposure: Initial Evidence and Future Directions
}

OPEN ACCESS

Edited by:

Christopher James Gidlow,

Staffordshire University,

United Kingdom

Reviewed by:

Simon Bell,

The University of Edinburgh,

United Kingdom

Sjerp De Vries,

Wageningen University \& Research,

Netherlands

*Correspondence:

Meredith S. Berry

mberry@ufl.edu

Specialty section:

This article was submitted to

Environmental Psychology,

a section of the journal

Frontiers in Psychology

Received: 31 July 2019

Accepted: 22 June 2020

Published: 14 July 2020

Citation:

Berry MS, Repke MA, Metcalf AL and Jordan KE (2020) Promoting Healthy Decision-Making via Natural

Environment Exposure: Initial

Evidence and Future Directions.

Front. Psychol. 11:1682.

doi: 10.3389/fpsyg.2020.01682

\begin{abstract}
Meredith S. Berry ${ }^{1,2 *}$, Meredith A. Repke ${ }^{3}$, Alexander L. Metcalf ${ }^{4}$ and Kerry E. Jordan ${ }^{5}$
${ }^{1}$ Human Behavioral Pharmacology and Decision-Making Laboratory, Department of Health Education and Behavior, University of Florida, Gainesville, FL, United States, ${ }^{2}$ Department of Psychology, University of Florida, Gainesville, FL, United States, ${ }^{3}$ Department of Psychology, University of Montana, Missoula, MT, United States, ${ }^{4}$ Department of Society and Conservation, University of Montana, Missoula, MT, United States, ${ }^{5}$ Department of Psychology, Utah State University, Logan, UT, United States
\end{abstract}

Research within psychology and other disciplines has shown that exposure to natural environments holds extensive physiological and psychological benefits. Adding to the health and cognitive benefits of natural environments, evidence suggests that exposure to nature also promotes healthy human decision-making. Unhealthy decision-making (e.g., smoking, non-medical prescription opioid misuse) and disorders associated with lack of impulse control [e.g., tobacco use, opioid use disorder (OUD)], contribute to millions of preventable deaths annually (i.e., 6 million people die each year of tobaccorelated illness worldwide, deaths from opioids from 2002 to 2017 have more than quadrupled in the United States alone). Impulsive and unhealthy decision-making also contributes to many pressing environmental issues such as climate change. We recently demonstrated a causal link between visual exposure to nature (e.g., forests) and improved self-control (i.e., decreased impulsivity) in a laboratory setting, as well as the extent to which nearby nature and green space exposure improves self-control and health decisions in daily life outside of the experimental laboratory. Determining the benefits of nearby nature for self-controlled decision-making holds theoretical and applied implications for the design of our surrounding environments. In this article, we synergize the overarching results of recent research endeavors in three domains including the effects of nature exposure on (1) general health-related decision-making, (2) health and decision-making relevant for application to addiction related processes (e.g., OUD), and (3) environmentally relevant decision-making. We also discuss key future directions and conclusions.

Keywords: environment, delay discounting, impulsivity, addiction, decision-making, nature, conservation, sustainability

\section{INTRODUCTION}

For decades environmental psychologists have extensively documented the multiple benefits to humans resulting from nature exposure. Although additional replication and extensions are needed, these benefits include a plethora of physiological and psychological improvements to human health including reduced recovery time following surgery, health improvements in patients with cancer (e.g., increased expression of anti-cancer antibodies), reduced hypertension, reduced stress, and increased happiness (Ulrich, 1984; Li et al., 2008; Mao et al., 2012; Thompson et al., 2012; 
White et al., 2013; see Twohig-Bennett and Jones, 2018 for a review and meta-analysis of health outcomes and greenspace exposure; see Houlden et al., 2018, for a review of the relationship between greenspace and mental wellbeing in adults). There is also recent evidence that suggests nature exposure could be a beneficial adjunctive treatment option in addition to traditional pharmacotherapy for individuals who suffer from disorders associated with lack of impulse control (e.g., addictionrelated disorders, evidence from various fields reviewed in detail below). Despite these well-documented benefits of nature exposure to human health, we as humans continue to degrade our natural environments. The most critical environmental and public health crises that contribute to degradation of natural spaces (e.g., species extinction, forest degradation, accelerated climate change resulting from anthropogenic influence, millions of premature deaths annually resulting from emissions/poor air quality) are a direct result of human decision-making and behavior (Chivian and Bernstein, 2008).

For example, despite climate scientists' account of current emissions as "dangerous to extremely dangerous" (Anderson and Bows, 2011), anthropogenic influenced global carbon emissions have surpassed the worst scenarios predicted by the Intergovernmental Panel on Climate Change (Boden and Blasing, 2010). Relatedly - poor air quality resulting from emissions is one of the leading causes of premature death worldwide - with nearly seven million mortalities occurring globally each year (World Health Organization [WHO], 2014, 2015, 2017). The direct contribution of human behavior (e.g., emissions from industries, factories, extensive private car use, air travel) in driving negative environmental outcomes (e.g., poor air quality, climate change) and resulting detrimental human health consequences (e.g., premature death) are well-documented and highly publicized.

In this manuscript we focus on the effects of nature exposure on decision-making processes relevant for human and environmental health. We will briefly synthesize findings and discuss future directions across key domains (1) at the intersection of nature exposure and human health related decision-making, (2) the potential for novel extensions combining health benefits and decision-making benefits of nature exposure to addiction research, and (3) the effects of nature exposure on environmentally relevant decision-making. The present manuscript is not an exhaustive literature review, but rather designed to briefly emphasize key discussion points and identify promising future directions related to nature exposure.

\section{NATURE EXPOSURE, HEALTH, AND HEALTH RELATED DECISION-MAKING}

Our work has primarily focused on determining mechanisms that influence decision-making to result in healthier decisions for both humans and ecosystems. For example, decades of research have demonstrated that exposure to natural (e.g., forests, lakes) as opposed to built (e.g., cities, buildings) environments reduces stress (Ulrich et al., 1991; Thompson et al., 2012), enhances attention (Faber Taylor et al., 2001; Berto, 2005), and improves mood (Bowler et al., 2010). Beyond these psychological benefits, biodiversity is also crucial to our physical health for medicines, medical research, combating infectious diseases, and food production. Adding to the research on health and cognitive benefits of natural environments, this team's research is among the first to show that not only cognition, but also behavior, choice and delay discounting are influenced differently as a function of natural versus built environmental exposure. Delay discounting refers to the decrease in value of an outcome with delay to receiving that outcome (Mazur, 1987). A delay discounting task evaluates choices between smaller sooner and larger later outcomes across a range of delays (e.g., $\$ 50$ now or $\$ 100$ in 5 years). A consistent pattern of choice of the smaller sooner outcomes is thought to represent relative "impulsive" decision-making. Delay discounting is one behavioral measure of "impulsivity." Impulsivity has a number of different meanings (e.g., inability to delay gratification) and can be measured in different ways. High rates of delay discounting (i.e., "impulsive" decision-making) are associated with a host of maladaptive behaviors including cigarette smoking, opioid abuse, and gambling (see Odum et al., 2000; Dixon et al., 2003; Kirby and Petry, 2004; Mitchell, 2004a,b). Delay discounting, therefore, may represent a target for intervention for health-relevant behavioral processes. At present delay discounting is thought to be one of the most valuable decision-making predictors of human behavior both within the laboratory and real-world decision-making contexts (Chabris et al., 2008).

Some evidence shows choices in other delay of gratification tasks are more "self-controlled" (i.e., less impulsive) with exposure to nature as opposed to built environments. Faber Taylor et al. (2002) demonstrated that among children living in the inner city, the more natural a girl's view from home was, the more "self-controlled" she was on a modified version of the classic marshmallow task (this same relation was not true for boys). van der Wal et al. (2013) also found that visual exposure to photographs of natural scenes on a computer screen resulted in less impulsive decision-making in a delay discounting task than photographs of built scenes. In a follow-up experiment, similar results were obtained when participants walked through either natural landscape environments or built landscape environments and then chose between receiving money now or in the future. Our lab has also shown that individuals visually exposed to natural environments exhibit more self-controlled decisions, while individuals exposed to built environments demonstrate more impulsive decisions in a monetary delay-discounting task (Berry et al., 2014; see Figure 1; Berry et al., 2015), and this effect may be related to expanded time and space perception (Berry et al., 2015; Repke et al., 2018).

Specifically, elongated time perception resulting from visual exposure to natural environments, could be a key mechanism underlying increased self-control with exposure to nature (Berry et al., 2015). It is possible that an expanded time perception window may facilitate bridging the gap between current decisions and future consequences of those decisions. The extent to which nearby nature and green space exposure improves self-control and health decisions in daily life outside of the experimental laboratory, however, has remained unexamined until recently, but holds applied implications for the design of our 


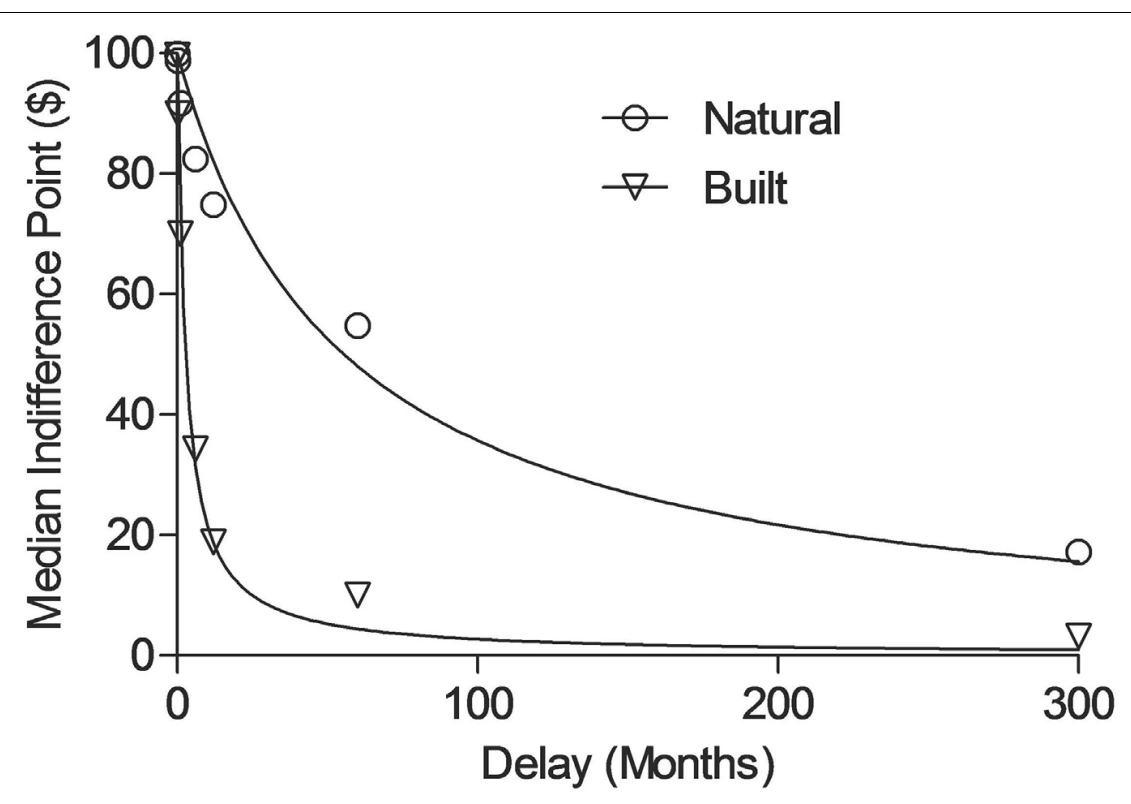

FIGURE 1 | In this study, participants viewed photographs of either natural or built scenes on the computer screen prior to engaging in the delay discounting task and time perception task (see Berry et al., 2015 for additional details). The data points represent median indifference points (i.e., the subjective value) as a function of delay (months) for natural (circles) and built (triangles) conditions. Lines show the best fit of the non-linear regression equation to the median indifference points (see Berry et al., 2015 for additional details). The "steeper" curve shows more impulsive decision-making (built) and the shallower curve shows more "self-controlled" decision-making in the delay discounting task.

surrounding environments to promote healthy decision-making for individuals and surrounding ecosystems, as well as happiness and general well-being. We recently conducted two studies to test a new model linking the health benefits of nature exposure to reduced impulsivity in decision-making. We determined in a real world national United States sample, participants' geospatial proximity to nature by quantifying the natural land cover surrounding participants' home addresses using remotely sensed data. Measures of nature accessibility predicted reduced "impulsive" decision-making in a delay discounting task, and also showed significant indirect effects through impulsive decisionmaking on depression and anxiety measures and general health and well-being. We paired this study with a laboratory-based paradigm and found that visual exposure to nature expanded perceptions of space, and while the indirect effects of nature exposure through space perception on impulsive decisionmaking did not meet conventional standards of significance $(p<0.10)$, the pattern was consistent with hypotheses. This combination of ecologically valid and experimental methods offers promising support for an impulsivity-focused model explaining the nature-health relationship (Repke et al., 2018).

\section{EXTENDING CURRENT APPLICATIONS OF NATURE EXPOSURE AND HEALTH DECISION-MAKING TO ADDICTION-RELATED RESEARCH}

Further extending and interweaving the above health-relevant decision-making models directly to addiction research, we recently proposed nature exposure as an adjunctive treatment option for opioid use disorder (OUD) in addition to traditional agonist pharmacotherapy treatment (e.g., methadone; Berry, under review). From 2002 to 2017 in the United States alone, deaths from opioid overdose have more than quadrupled (National Institutes on Drug Abuse, 2018). Relatedly, pain represents the leading cause of disability in the United States, affecting more Americans than diabetes, heart disease, and cancer combined (National Institutes of Health, 2019). The demand for opioid medication to effectively treat pain has contributed to the surging opioid crisis. More than 100,000 people begin opioid maintenance treatment (OMT) annually (Substance Abuse and Mental Health Services Administration [Samhsa] and Center for Behavioral Health Statistics and Quality, 2014), which is the standard of care. However (and paradoxically), OMT patients often experience or develop a heightened sensitivity to pain (hyperalgesia; Dunn et al., 2015), and have high rates of stress and affective and anxiety-related comorbidities (Hyman et al., 2007; Sinha, 2008; Gros et al., 2013). These conditions are interactive with other behavioral and environmental correlates of opioid and other substance use disorders including "impulsive" decision-making (e.g., harmful opioid use is associated with increased delay discounting), and a lack of alternative (i.e., substance free) and social (e.g., strong friendships and/or romantic relationships) reinforcement.

A promising, novel adjunct treatment option that could preserve the benefits of OMT and simultaneously improve pain management, decrease stress and anxiety, reduce behavioral correlates associated with OUD (e.g., "impulsivity" in delay discounting, or real world decision-making underscoring delay 
discounting processes in every day life, such as a choice between an immediate drug high over longer term healthy family relationships), as well as enhance alternative and substance free sources of reinforcement, may be exposure to nature and/or green space. Green light - similar to that in green spaces - has analgesic properties and reduces experimental pain in animal models (Ibrahim et al., 2017), an effect which appears to be mediated through the visual and opioid systems, and more. This effect has cross-species generality, showing that green light reduces pain intensity of migraines (Noseda et al., 2016), and nature scene murals placed at the bedside (as well as nature sounds in the background) during a flexible bronchoscopy procedure reduced self-reported pain compared to a control condition. This effect remained after controlling for age, gender, race, health status, and medication doses (Diette et al., 2003).

As discussed previously, research also shows exposure to nature (including green space) decreases anxiety, stress, and depression, which are common comorbid conditions among individuals with opioid use and other substance use disorders (Kushner et al., 1990, 2008; Koob and Schulkin, 2019). Access to green space and nature is also associated with reductions in craving of various substances (Martin et al., 2019). Given the strong relations between delay discounting and harmful opioid use that could serve as a potential therapeutic target, we reiterate that visual and actual exposure to natural environments also decreases "impulsive" decision-making in delay discounting tasks (e.g., van der Wal et al., 2013; Berry et al., 2015). Finally, individuals living farther away from recreational outlets (including parks and green space) and have less access to pleasant activities have higher rates of substance use, including prescription opioid use (Leventhal et al., 2015). Taken together, nature exposure could serve as a promising adjunctive treatment option for opioid abuse. However, little if any systematic research exists to inform this topic.

\section{NATURE EXPOSURE AND ENVIRONMENTALLY RELEVANT DECISION-MAKING}

In additional to personally relevant health decision-making, exposure to nature (either simulated or actual) may also promote environmentally relevant decision-making. Researchers have previously discussed the potential of nature exposure itself as a pro-environmental behavior trigger through various mechanisms (Annerstedt van den Bosch and Depledge, 2015). Zelenski et al. (2015) showed that people engage in futureoriented decisions that help to promote cooperation, conserve resources and behave more sustainably for themselves and team members in a public goods game after viewing videos of natural versus built environments These findings suggest that exposure to natural as opposed to built environments are not only beneficial for cognition, stress, and mood, but might also lead to healthier behaviors for individuals and ecosystems via improved global decision-making processes (i.e., decision-making across more than one domain, for example, money and health related decision-making, see Odum, 2011). These results have important implications for how we structure and design our environments (e.g., more green spaces in cities to promote future-oriented decision-making), as well as the impetus to preserve natural environments for human and ecological well-being.

Delay discounting, which has been proposed as a behavioral measure of sustainability (more sustainable associated with more "self-controlled" decision-making) and could serve as a global target for intervention. Few studies, however, have directly examined this concept in terms of environmentally relevant decision-making. Hardisty and Weber (2009) examined delay discounting of hypothetical financial, air quality, and health gains and losses scenarios across two delays. Within-subject analyses revealed that individuals who discounted gains steeply ("impulsively") in one realm (e.g., monetary) also discounted gains steeply ("impulsively") in other realms (e.g., air quality, health) and vice versa (see also Meyer, 2013; Johnson and Saunders, 2014; Kaplan et al., 2014; Richards and Green, 2015 for examples of environmental commodity discounting/support for long-term conservation goals). Extending this line of work Berry et al. (2017a,b) showed that mechanisms similar to those driving decisions for monetary outcomes might also be driving decisions about air quality (and possibly other ecological outcomes). This line of research lends support to targeting the same underlying mechanisms to facilitate reduction of delay discounting ("impulsivity") on a global scale (see Odum, 2011). Therefore, reductions in monetary delay discounting as have been previously shown through various techniques (e.g., exposure to nature, van der Wal et al., 2013; Berry et al., 2015; future episodic thought, Peters and Büchel, 2010; for a review see Koffarnus et al., 2013) may also reduce delay discounting of air quality or other ecological commodities. Reducing delay discounting of environmental commodities could hold relevance for real-world environmentally relevant decision-making. We have further combined the above lines of research to determine if exposure to natural environments also decreases "impulsive" air quality choices. Evidence suggests that individuals respond in a more self-controlled way for ecological decisions related to air quality with exposure to natural as opposed to built environments (Berry et al., 2019). These results were associated with expanded space perception as previously shown (e.g., Repke et al., 2018). Although an initial foundation, this research still represents an area that has much opportunity for growth.

\section{CONCLUSION}

More research is needed to further understand mechanistic drivers of behavior change with exposure to natural environments, and to test and expand these findings beyond laboratory settings. Exposure to natural environments provides a myriad of psychological benefits, and may also be useful as adjunctive treatments for addictive disorders (specifically OUD). Beyond personal health and wellness benefits, exposure to nature may also prove valuable for environmentally relevant decision-making.

As previously noted, there have been too few systematic experiments examining the potential of nature exposure as an 
adjunctive treatment for addiction (e.g., OUD) and disorders associated with lack of impulse control. This is also true of environmental decision-making in the context of nature exposure and actual behavior change outside of laboratory settings (i.e., not self-report data, although of course self-report data can be informative in different ways; please see Steg and Vlek, 2009 for review and commentary). Further, many of the studies reviewed here (and in the literature) focus on shortterm effects. There is a need for longer-term and longitudinal studies to understand sustained benefits of nature exposure on psychological, health, decision-making and environmental outcomes. Experimental analysis of behavior might hold useful tools for identifying factors that increase or decrease discounting of environmental commodities - which could help shift individual and societal decision-making toward both longterm conservation and health-oriented behaviors. Of primary importance will be determining whether similar underlying processes drive environmental decision-making as monetary decision-making; and if these processes do share underlying mechanisms, reduction of impulsivity may be approached on a more global scale (see Odum, 2011 for discussion), holding implications for health, treatment of disorders associated with lack of impulse control such as OUD, and environmentally relevant decision-making.

\section{REFERENCES}

Anderson, K., and Bows, A. (2011). Beyond 'dangerous' climate change: emission scenarios for a new world. Philos. Trans. R. Soc. A 369, 20-44. doi: 10.1098/rsta. 2010.0290

Annerstedt van den Bosch, M., and Depledge, M. H. (2015). Healthy people with nature in mind. BMC Public Health 15:1232. doi: 10.1186/s12889-015-2574-8

Berry, M. S., Friedel, J. E., DeHart, W. B., Mahamane, S., Jordan, K. E., and Odum, A. L. (2017a). The value of clean air: comparing discounting of delayed air quality and money across magnitudes. Psychol. Record 67, 137-148. doi: 10.1007/s40732-017-0233-4

Berry, M. S., Nickerson, N. P., and Odum, A. L. (2017b). Delay discounting as an index of sustainable behavior: devaluation of future air quality and implications for Public Health. Int. J. Environ. Res. Public Health 14, 997-1011.

Berry, M. S., Nickerson, N. P., and Covelli Metcalf, L. (2016). Using spatial, economic, and ecological opinion data to inform gray wolf conservation. Wildl. Soc. Bull. 40, 554-563. doi: 10.1002/wsb.687

Berry, M. S., Repke, M. A., and Conway, L. G. III. (2019). Visual exposure to natural environments decreases delay discounting of improved air quality. Front. Public Health 7:308. doi: 10.3389/fpubh.2019.00308

Berry, M. S., Repke, M. A., Nickerson, N. P., Conway, L. G. III, Odum, A. L., and Jordan, K. E. (2015). Making time for nature: visual exposure to natural environments lengthens subjective time perception and reduces impulsivity. PLoS One 10:e141030. doi: 10.1371/journal.pone.014 1030

Berry, M. S., Sweeney, M. M., Morath, J., Odum, A. L., and Jordan, K. E. (2014). The nature of impulsivity: visual exposure to natural environments decreases impulsive decision-making in a delay discounting task. PLoS One 9:e97915. doi: 10.1371/journal.pone.0097915

Berto, R. (2005). Exposure to restorative environments helps restore attention capacity. J. Environ. Psychol. 25, 249-259. doi: 10.1016/j.jenvp.2005.07.001

Boden, T., and Blasing, T. J. (2010). Record High Global Carbon Dioxide Emissions. California: Carbon Dioxide Information Analysis Center.

Bowler, D. E., Buyung-Ali, L. M., Knight, T. M., and Pullin, A. S. (2010). A systematic review of evidence for the added benefits to health of exposure to natural environments. BioMedCentral Public Health 10, $456-465$.

\section{ETHICS STATEMENT}

Ethical review and approval was not required for the study on human participants in accordance with the local legislation and institutional requirements. Written informed consent for participation was not required for this study in accordance with the national legislation and the institutional requirements.

\section{AUTHOR CONTRIBUTIONS}

MB synthesized the literature and wrote the original draft of the manuscript. All authors contributed to the conceptualization and review and editing of the manuscript draft.

\section{FUNDING}

$\mathrm{MB}$ was funded in part by the National Institute on Drug Abuse Grant T32DA07209, and was also funded in part by the National Science Foundation under Grant EPS 1101342. Any opinions, findings, and conclusions or recommendations expressed in this material are those of the authors and do not necessarily reflect the views of the National Science Foundation.

Chabris, C. F., Laibson, D., Morris, C. L., Schuldt, J. P., and Taubinsky, D. (2008). Individual laboratory-measured discount rates predict field behavior. J. Risk Uncertain. 37, 237-269. doi: 10.1007/s11166-008-9053-x

Chivian, E., and Bernstein, A. (2008). "Preface," in Sustaining Life: How Human Health Depends on Biodiversity, eds E. Chivian, and A. Bernstein (New York, NY: Oxford University Press, Inc.), XI-XIII.

Diette, G. B., Lechtzin, N., Haponik, E., Devrotes, A., and Rubin, H. R. (2003). Distraction therapy with nature sights and sounds reduces pain during flexible bronchoscopy: a complementary approach to routine analgesia. Chest 123, 941-948. doi: 10.1378/chest.123.3.941

Dixon, M. R., Marley, J., and Jacobs, E. A. (2003). Delay discounting by pathological gamblers. J. Appl. Behav. Anal. 36, 449-458. doi: 10.1901/jaba.2003.36-449

Dunn, K. E., Finan, P. H., Tompkins, D. A., Fingerhood, M., and Strain, E. C. (2015). Characterizing pain and associated coping strategies in methadone and buprenorphine-maintained patients. Drug Alcohol Depend 157, 143-149. doi: 10.1016/j.drugalcdep.2015.10.018

Faber Taylor, A., Kuo, F. E., and Sullivan, W. C. (2001). Coping with ADD: the surprising connection to green play settings. Environ. Behav. 33, 54-77. doi: $10.1177 / 00139160121972864$

Faber Taylor, A., Kuo, F. E., and Sullivan, W. C. (2002). Views of nature and selfdiscipline: evidence from inner city children. J. Environ. Psychol. 22, 49-63. doi: 10.1006/jevp.2001.0241

Gros, D. F., Milanak, M. E., Brady, K. T., and Back, S. E. (2013). Frequency and severity of comorbid mood and anxiety disorders in prescription opioid dependence. Am. J. Addict. 22, 261-265. doi: 10.1111/j.1521-0391.2012. 12008.x

Hardisty, D. J., and Weber, E. U. (2009). Discounting future green: money versus the environment. J. Exp. Psychol. Gen. 138, 329-340. doi: 10.1037/a0016433

Houlden, V., Weich, S., Porto de Albuquerque, J., Jarvis, S., and Rees, K. (2018). The relationship between greenspace and the mental wellbeing of adults: a systematic review. PLoS One 13:e0203000. doi: 10.1371/journal.pone.0203000

Hyman, S. M., Fox, H., Hong, K. I., Doebrick, C., and Sinha, R. (2007). Stress and drug-cue-induced craving in opioid-dependent individuals in naltrexone treatment. Exp. Clin. Psychopharmacol. 15, 134-143. doi: 10.1037/1064-1297. 15.2.134

Ibrahim, M. M., Patwardhan, A., Gilbraith, K. B., Moutal, A., Yang, X., Chew, L. A., et al. (2017). Long-lasting antinociceptive effects of green light in acute 
and chronic pain in rats. Pain 158, 347-360. doi: 10.1097/j.pain.0000000000 000767

Johnson, A. E., and Saunders, D. K. (2014). Time preferences and the management of coral reef fisheries. Ecol. Econ. 100, 130-139. doi: 10.1016/j.ecolecon.2014. 01.004

Kaplan, B., Reed, D., and McKerchar, T. (2014). Using a visual analogue scale to assess delay, social, and probability discounting of an environmental loss. Psychol. Record 64, 261-269. doi: 10.1007/s40732-014-0041-z

Kirby, K. N., and Petry, N. M. (2004). Heroin and cocaine abusers have higher discount rates for delayed rewards than alcoholics or non-drug-using controls. Addiction, 99, 461-471. doi: 10.1111/j.1360-0443.2003.00669.x

Koffarnus, M. N., Jarmolowicz, D. P., Mueller, E. T., and Bickel, W. K. (2013). Changing delay discounting in the light of the competing neurobehavioral decision systems theory: a review. J. Exp. Anal. Behav. 99, 32-57. doi: 10.1002/ jeab. 2

Koob, G. F., and Schulkin, J. (2019). Addiction and stress: an allostatic view. Neurosci. Biobehav. Rev. 106, 245-262. doi: 10.1016/j.neubiorev.2018. 09.008

Kushner, M. G., Krueger, R. G., Frye, B. G., and Peterson, J. G. (2008). "Epidemiological perspectives on co-occurring anxiety disorder and substance use disorder," in Anxiety and Substance Use Disorders. Series in Anxiety and Related Disorders, eds S. H. Stewart, and P. J. Conrod (Boston, MA: Springer).

Kushner, M. G., Sher, K. J., and Beitman, B. D. (1990). The relation between alcohol problems and the anxiety disorders. Am. J. Psychiatry 147, 685-695. doi: 10.1176/ajp.147.6.685

Leventhal, A. M., Bello, M. S., Unger, J. B., Strong, D. R., Kirkpatrick, M. G., and Audrain- McGovern, J. (2015). Diminished alternative reinforcement as a mechanism underlying socioeconomic disparities in adolescent substance use. Prev. Med. 80, 75-81. doi: 10.1016/j.ypmed.2015.05.021

Li, Q., Morimoto, K., Kobayashi, M., Inagaki, H., Katsumata, M., Hirata, Y., et al. (2008). Visiting a forest, but not a city, increases human natural killer activity and expression of anti-cancer proteins. Int. J. Immunopathol. Pharmacol. 21, 117-127. doi: 10.1177/039463200802100113

Mao, G. X., Cao, Y. B., Lan, X. G., He, Z. H., Chen, Z. M., Wang, Y. Z., et al. (2012). Therapeutic effect of forest bathing on human hypertension in the elderly. J. Cardiol. 60, 295-502.

Martin, L., Pahl, S., White, M. P., and May, J. (2019). Natural environments and craving: the mediating role of negative affect. Health Place 58, 1-7. doi: 10.1016/ j.healthplace.2019.102160

Mazur, J. E. (1987). “An adjusting procedure for studying delayed reinforcement," in Quantitative Analyses of Behavior: The Effect of Delay and of Intervening Events on Reinforcement Value, Vol. 5, eds M. L. Commons, J. E. Mazur, J. A. Nevin, and H. Rachlin (Hillsdale, NJ: Earlbaum), 55-73.

Meyer, A. (2013). Intertemporal valuation of river restoration. Environ. Resour. Econ. 54, 41-61. doi: 10.1007/s10640-012-9580-4

Mitchell, S. H. (2004a). Effects of short-term nicotine deprivation on decisionmaking: delay, uncertainty and effort discounting, Nicotine Tob. Res. 6, 819828. doi: 10.1080/14622200412331296002

Mitchell, S. H. (2004b). Measuring impulsivity and modeling its association with cigarette smoking. Behav. Cogn. Neurosci. Rev. 3, 261-275. doi: 10.1177/ 1534582305276838

National Institutes of Health. (2019). Pain Management. Available online at: https: //report.nih.gov/nihfactsheets/ViewFactSheet.aspx?csid=57

National Institutes on Drug Abuse (2018). Overdose Death Rates [Homepage on the Internet]. North Bethesda, MA: National Institute on Drug Abuse.

Noseda, R., Bernstein, C. A., Nir, R.-R., Lee, A. J., Fulton, A. B., Bertisch, S. M., et al. (2016). Migraine photophobia originating in cone-driven retinal pathways. Brain 139, 1971-1986. doi: 10.1093/brain/aww119

Odum, A. L. (2011). Delay discounting: trait variable? Behav. Processes 87, 1-9. doi: 10.1016/j.beproc.2011.02.007

Odum, A. L., Madden, G. J., Badger, G. J., and Bickel, W. K. (2000). Needle sharing in opioid-dependent outpatients: psychological processes underlying risk. Drug Alcohol Depend. 60, 259-266. doi: 10.1016/s0376-8716(00) 00111-3
Peters, J., and Büchel, C. (2010). Episodic future thinking reduces reward delay discounting through an enhancement of prefrontal mediotemporal interactions. Neuron 66, 138-148.doi: 10.1016/j.neuron.2010. 03.026

Repke, M. A., Berry, M. S., Conway, L. G. I. I. I., Metcalf, A., Hensen, R. M., and Phelan, C. (2018). How does nature exposure make people healthier?: evidence for the role of impulsivity and expanded space perception. PLoS One 13:e0202246. doi: 10.1371/journal.pone.0202246

Richards, T. J., and Green, G. P. (2015). Environmental choices and hyperbolic discounting: an experimental analysis. Environ. Resour. Econ. 62, 83-103. doi: 10.1007/s10640-014-9816-6

Sinha, R. (2008). Chronic stress, drug use, and vulnerability to addiction. Ann. N. Y. Acad. Sci. 1141, 105-130. doi: 10.1196/annals.1441.030

Steg, L., and Vlek, C. (2009). Encouraging pro-environmental behaviour: an integrative review and research agenda. J. Environ. Psychol. 29, 309-317. doi: 10.1016/j.jenvp.2008.10.004

Substance Abuse and Mental Health Services Administration [Samhsa] and Center for Behavioral Health Statistics and Quality, (2014). "Treatment episode data set(TEDS) 2002-2012. National admissions to substance abuse treatment services," in HHS Publication No. (SMA) 14- 4850 (Rockville, MD: Substance Abuse and Mental Health Services Administration). 2014.BHSIS Series S-71.

Thompson, W. C., Roe, J., Aspinall, P., Mitchell, R., and Clow, A. (2012). More green space is linked to less stress in deprived communities: evidence from salivary cortisol patterns. Landsc. Urban Plan. 105, 221-229. doi: 10.1016/j. landurbplan.2011.12.015

Twohig-Bennett, C., and Jones, A. (2018). The health benefits of the great outdoors: a systematic review and meta-analysis of greenspace exposure and health outcomes. Environ. Res. 166, 628-637. doi: 10.1016/j.envres.2018.06.030

Ulrich, R. (1984). through a window may influence recovery from surgery. Science 224, 420-421. doi: 10.1126/science.6143402

Ulrich, R. S., Simons, R. F., Losito, B. D., Fiorito, E., and Miles, M. A. (1991). Stress recovery during exposure to natural and urban environments. J. Environ. Psychol. 11, 201-230. doi: 10.1016/s0272-4944(05)80184-7

van der Wal, A. J., Schade, H. M., Krabbendam, L., and van Vugt, M. (2013). Do natural landscapes reduce future discounting in humans? Proc. R. Soc. Lon. B Biol. Sci. 280:20132295. doi: 10.1098/rspb.2013.2295

White, M., Alcock, I., Wheeler, B., and Depledge, M. H. (2013). Would you be happier living in a greener urban area? A fixed-effects analysis of panel data. Psychol. Sci. 24, 920-928. doi: 10.1177/0956797612464659

World Health Organization [WHO] (2014). Burden of Disease From Household Air Pollution for 2012. Avaliable online at: www.who.int/phe/health topics/outdoorair/databases/FINAL_HAP_AAP_BoD_24March2014.pdf?ua=1 (accessed December 2, 2016).

World Health Organization [WHO] (2015). Ambient (Outdoor) Air Quality and Health. Avaliable online at: http://www.who.int/mediacentre/factsheets/fs313/ en/ (accessed February 25, 2015).

World Health Organization [WHO] (2017). 7 Million Premature Deaths Annually Linked to Air Pollution. Avaliable online at: www.who.int/mediacentre/ news/releases/2014/air-pollution/en/ (accessed December 2, 2016).

Zelenski, J. M., Dopko, R. L., and Capaldi, C. A. (2015). Cooperation is in our nature: nature exposure may promote cooperative and environmentally sustainable behavior. J. Environ. Psychol. 42, 24-31. doi: 10.1016/j.jenvp.2015. 01.005

Conflict of Interest: The authors declare that the research was conducted in the absence of any commercial or financial relationships that could be construed as a potential conflict of interest.

Copyright (C) 2020 Berry, Repke, Metcalf and Jordan. This is an open-access article distributed under the terms of the Creative Commons Attribution License (CC BY). The use, distribution or reproduction in other forums is permitted, provided the original author(s) and the copyright owner(s) are credited and that the original publication in this journal is cited, in accordance with accepted academic practice. No use, distribution or reproduction is permitted which does not comply with these terms. 